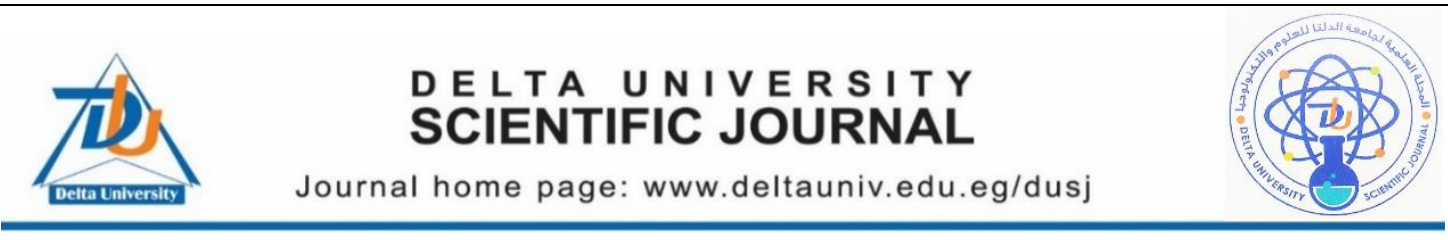

\title{
THERAPEUTIC EFFECT OF THE CURCUMIN IN CISPLATIN-INDUCED KIDNEY FIBROSIS EXPERIMENTALLY IN RATS
}

\section{Abd alkareem Omar Maghmomeh \\ Department of Biochemistry, Faculty of Pharmacy, Delta University for Science and Technology, International Coastal Road, Gamasa city, Mansoura}

\begin{abstract}
Kidney fibrosis is the common final pathway of virtually all progressive injury to the kidney and a promising therapeutic target in chronic kidney disease (CKD). Curcumin has renal protective properties against kidney fibrosis. The exact mechanism of such protection is not clear. Therefore, this study was conducted to examine the molecular levels of the protective effect of curcumin on cisplatin induced fibrosis in rats. We investigated the effects of curcumin in kidney fibrosis which was induced in male Sprague Dawley rats using cisplatin $(4.5 \mathrm{mg} / \mathrm{kg}$ in 2 consecutive days). Curcumin was administered by oral tubes $200 \mathrm{mg} / \mathrm{kg}$ daily for 21 days. Serum creatinine, creatinine clearance, urea nitrogen and oxidative stress markers [glutathione (GSH), lipid peroxide (Malondialdehyde)] assessments of these parameters were carried out to indicate the effect of curcumin in kidney fibrosis. Serum analysis revealed an alteration in parameters of kidney. A decrease in the antioxidant activity of kidney was recorded in cisplatin group while curcumin administration restored it. The results clarified the strong protective effect of curcumin on cisplatin induced kidney fibrosis in rats.
\end{abstract}

\section{Keywords}

Kidney fibrosis; Oxidative stress; Curcumin.

\section{Introduction}

Chronic kidney disease is defined as a progressive loss in renal function over a time. According to the United States Renal Data System, the highest prevalence was found in Taiwan, with 2447 patients per million, and the lowest prevalence was in Philippines, at $110 \mathrm{ppm}$ [1]. In Egypt, the last statistics was performed in 2004, with a prevalence of $483 \mathrm{ppm}$ [2]. Kidney fibrosis develops when chronic kidney injury activates progenitor cells to repair tissue, but these multipotent cells often become dysfunctional with sustained injury and induce fibrogenic repair and excess cell growth [3]. The hallmark of kidney fibrosis is the accumulation of extracellular matrix proteins [4]. 
Cisplatin is one of the most widely used and most effective cytotoxic agents in the treatment of a variety of malignant tumors, including lung, colorectal, ovarian, breast, head/neck, bladder, and testicular cancers in both children and adults [5]. On the other hand, cisplatin drugs have two main limitations: their severe side effects and the ability of cancers to develop drug resistance. Common side effects of cisplatin drugs include nausea, vomiting, diarrhea, neuropathy, ototoxicity, hepatotoxicity and nephrotoxicity [6]. Patients develop acute kidney injury [7] which may progress to chronic kidney injury [8]. Renal involvement is common after cisplatin injection (up to $30-50 \%$ of the cases), and it most often occurs in the second week of treatment [9]. Renal damage has a wide spectrum of sign symptoms e.g. hematuria, proteinuria, glucosuria, hypomagnesemia and most notably acute kidney injury [10].Cisplatin-induced nephrotoxicity may range from mild and reversible structural alterations in tubular epithelial cells inducing a variable range of renal dysfunction (acute nephrotoxicity), to potentially irreversible renal failure leading to chronic and progressive renal insufficiency (chronic nephrotoxicity) [11].

The kidney is a highly vulnerable organ to damage caused by reactive oxygen species (ROS), due to the abundance of long-chain polyunsaturated fatty acids in the composition of renal lipids. Excessive ROS can induce apoptosis through both the extrinsic and intrinsic pathways [12]. ROS play a critical role in acute kidney injury, as well as progression to fibrosis [13]. Cisplatin also induces ROS that triggers cell death [14]. Cisplatin decreases antioxidant enzymes such as GSH and MDA due to excessive accumulation of ROS by cisplatin[15]

Curcumin is a naturally occurring compound derived from the rhizomes of Curcuma longa. It is a member of the ginger family Zingiberaceae, found in the rhizome of the herb Curcuma longa, which is commonly known as turmeric [16]. Turmeric is widely used in therapeutic preparations [17]. Curcumin has been found to possess several properties including antioxidant [18], antimicrobial [19], antiviral [20], anti-inflammatory [21], anti-carcinogenic [22] and anti-diabetic [23]. In the present study, we tested curcumin in an in vivo model of cisplatin-induced kidney fibrosis to assess its potential renoprotective effects.

\section{Materials and Methods}

\section{Chemicals and kits}

Curcumin was purchased from Sigma-aldrich (St. Louis, MO, USA). Creatinine, urea, malondialdehyde (MDA), reduced glutathione (GSH) and phosphate buffer saline (PBS) were purchased from Bio-diagnostic Co (Dokki, Giza, Egypt). Thiopental sodium was supplied in the form of (Anapental $500 \mathrm{mg} / \mathrm{vial}$ ), purchased from Sigma Tec Co., Egypt. 
Animals, Experimental protocols, and sampling

\section{Animals:}

This study comprised of 30 male Sprague Dawley rats 3 months old, weighing $(225 \pm 25 \mathrm{gm})$, were utilized in the present study. Rats were housed in stainless steel rodent cages at room temperature $\left(25 \pm 2^{\circ} \mathrm{C}\right)$ and with 12 hours dark/light cycle and were provided with standard rat food and water.

\section{Experimental protocols}

The experimental rats were divided into 3 groups $(\mathrm{n}=10)$ a) control group: rats was maintained on normal pellet diet. b) cisplatin group: rats were treated with was cisplatin (4.5 mg/ $\mathrm{kg}$.day/i.p) for 2 consecutive days [3] c) cisplatin + curcumin: (4.5 mg/ $\mathrm{kg}$.day) in 2 consecutive days [3], after 21 days of cisplatin injection [24], rats were orally administered curcumin was suspended in (PBS) $(200 \mathrm{mg} / \mathrm{kg} /$ day/) for 21 days. The dose and duration were selected according to a previous study [25].

At the end of study, the rats were placed in a metabolic cages for 24 hours to collect 24-hour urine, and samples were taken for estimating urine creatinine [26]. After 12 hours of fasting rats were sacrificed after anesthetization using thiopental sodium $(40 \mathrm{mg} / \mathrm{kg}$, IP of $2.5 \%$ thiopental). Blood samples were withdrawn from thiopentalanesthetized animals via retro-orbital puncture after a fast of 12 hours [27]. Serum was extracted after blood centrifugation for $10 \mathrm{~min}$ at $4000 \times \mathrm{g}$. Kidney tissues were removed and homogenized in $5 \mathrm{ml}$ ice-cold PBS (0.02 M, pH 7.4) (10\% $\mathrm{w} / \mathrm{v})$, centrifuged at $3000 \mathrm{rpm}$ for $20 \mathrm{~min}$ at $4{ }^{\circ} \mathrm{C}$ and kept at $-80^{\circ} \mathrm{C}$ until further analysis.

\section{Determination of biochemical parameters}

Serum creatinine, serum urea, urine creatinine, malondialdehyde (MDA) and reduced glutathione (GSH) were estimated in kidney tissue were assayed using calorimetric kits according to manufacturer's instructions.

\section{Statistical analysis}

Results are expressed as means \pm SD of 10 animals, and differences between groups were tested for significance using analysis of variance (ANOVA), followed by Turkey post hoc test. The level of statistical significance was taken at $P \leq 0.05$. Statistical analysis of the experimental data was performed using the statistical package SPSS as the definitive analyzer of drug effects.

\section{Ethics statement}

This study was carried out in strict accordance with the guidelines and authorization for the use of laboratory animals. The protocol was approved by the committee on the ethics of animal experiments of Faculty of Pharmacy, Delta University for science and technology, for Animal Use.

\section{Results}

Delta University for Science and Technology

Coastal International Road, Mansoura, Gamasa City, Dakahlia, Egypt

E-mail: dusj@deltauniv.edu.eg

Journal homepage: $\underline{w w w . d e l t a u n i v . e d u . e g / d u s j}$ 


\section{Effect of curcumin on kidney function:}

Creatinine and urea levels were significantly elevated in cisplatin group compared to control group significantly increased creatinine clearance level compared to cisplatin group ( $\mathrm{p}<0.05)$.
(Figure 1 \& Figure 2). However, creatinine clearance was significantly reduced in cisplatin group when compared to the control group ( $\mathrm{p}<$ 0.01)(Figure3).

Curcumin

treatments significantly reduced serum creatinine and urea levels in serum and

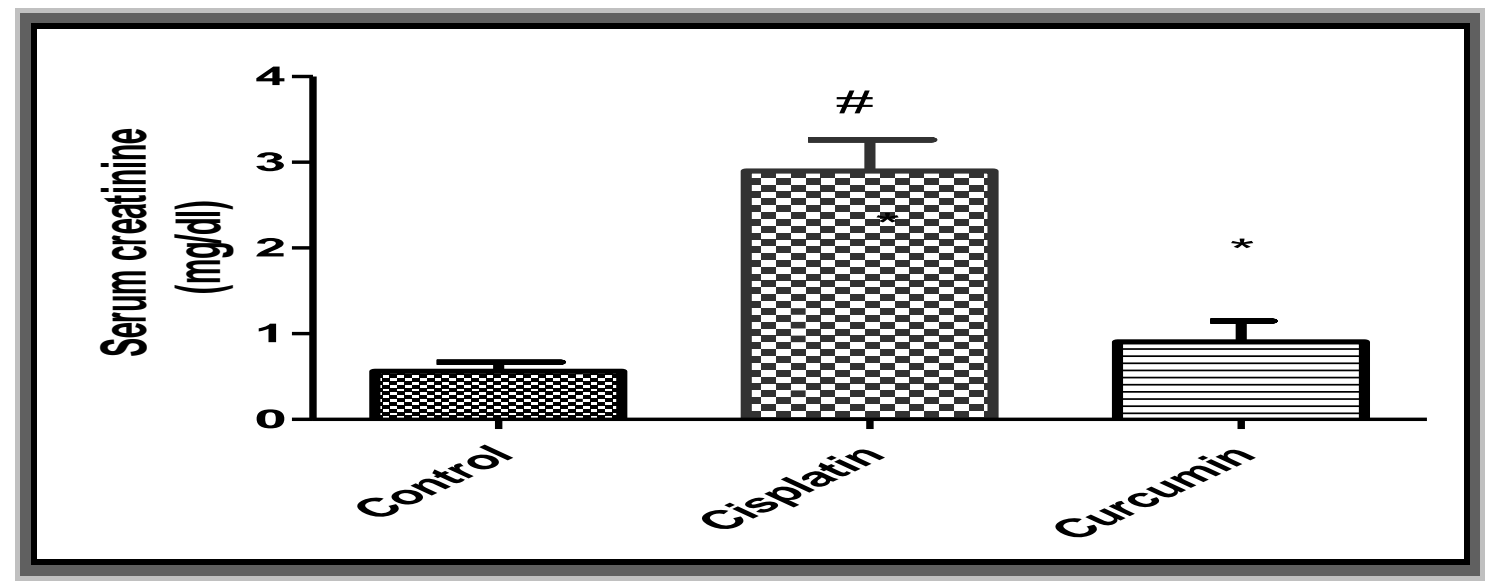

Figure 1 : Effect of curcumin $(200 \mathrm{mg} / \mathrm{kg} / \mathrm{day})$ on serum creatinine level.

Values: (Mean \pm SD).

\# = Significant against control group $\mathrm{p}<0.01$

$*=$ Significant against cisplatin group $\mathrm{p}<0.05$.

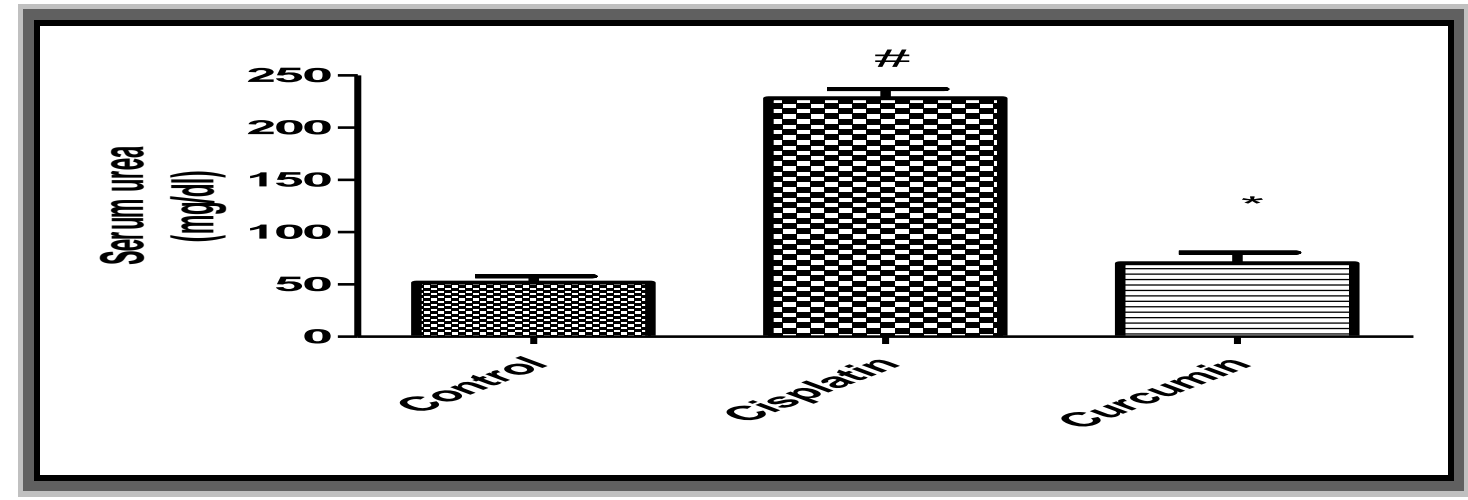

Figure 2: Effect of curcumin $(200 \mathrm{mg} / \mathrm{kg} /$ day $)$ on serum urea level.

Values: (Mean $\pm \mathrm{SD}$ ).

$\#=$ Significant against control group $\mathrm{p}<0.01$

$*$ = Significant against cisplatin group $\mathrm{p}<0.05$

Delta University for Science and Technology

Coastal International Road, Mansoura, Gamasa City, Dakahlia, Egypt

E-mail: dusj@deltauniv.edu.eg

Journal homepage: www.deltauniv.edu.eg/dusj 


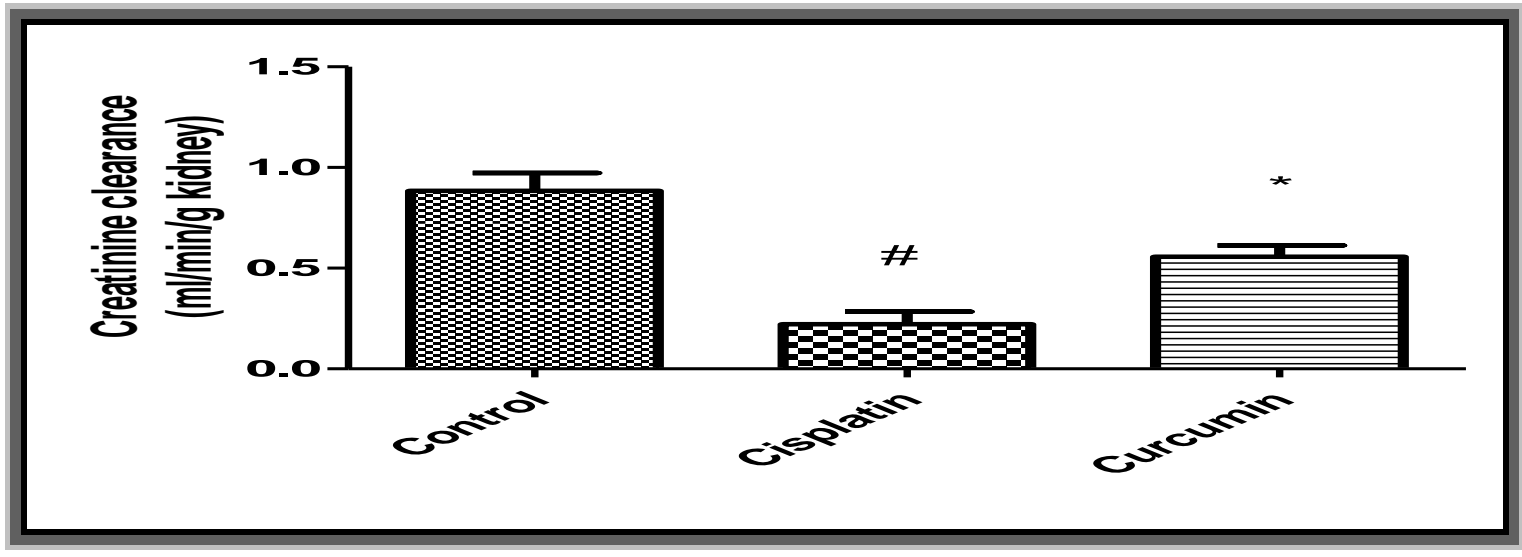

Figure 3 : Effect of curcumin $(200 \mathrm{mg} / \mathrm{kg} /$ day $)$ on creatinine clearance level.

Values: (Mean \pm SD).

\# = Significant against control group $\mathrm{p}<0.01$

$*=$ Significant against cisplatin group $\mathrm{p}<0.05$.

in Cisplatin group when compared to the control group ( $\mathrm{p}<0.01)$ (Figure 5). Curcumin treatments were significantly reduced MDA and were significantly increased GSH compared to cisplatin group $(\mathrm{p}<0.05)$.
Effect of curcumin on oxidative stress:

kidney MDA was significantly increased in cisplatin group compared to control group (Figure 4) however; kidney GSH was significantly reduced

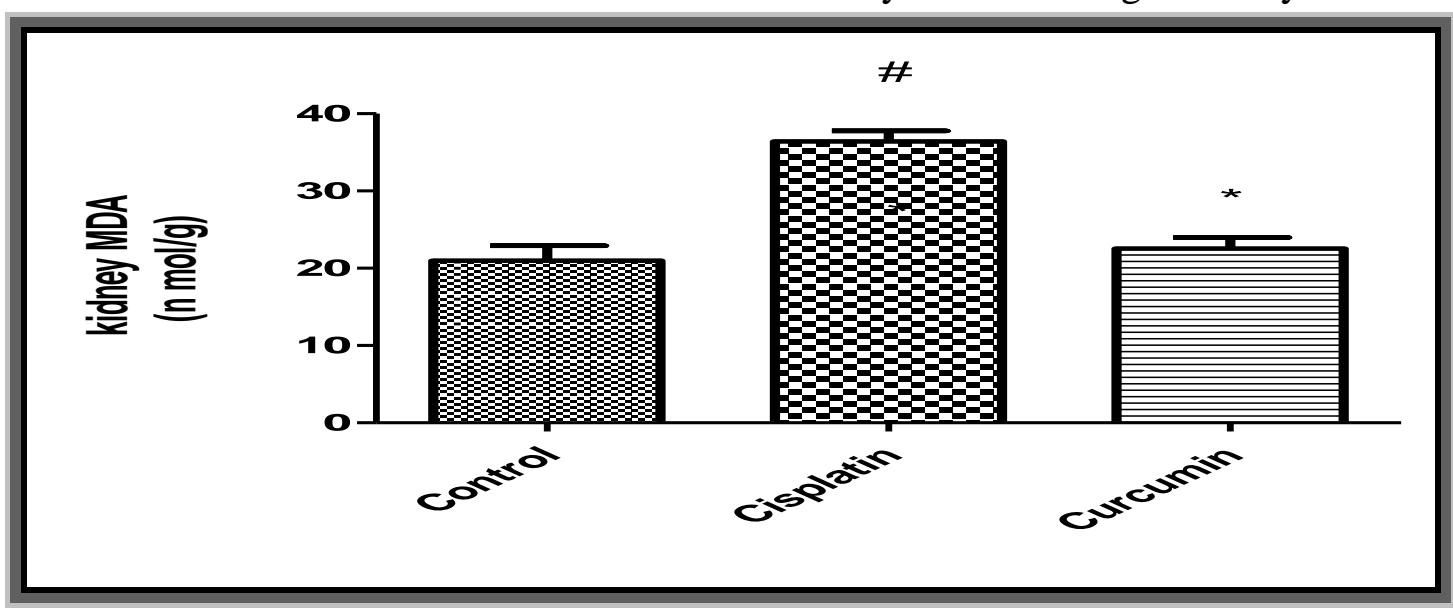

Figure 4: Effect of curcumin $(200 \mathrm{mg} / \mathrm{kg} / \mathrm{day})$ on kidney MDA level.

Values: (Mean $\pm \mathrm{SD})$.

\# = Significant against control group $\mathrm{p}<0.0^{\circ}$

$*=$ Significant against cisplatin group $p<0.05$.

Delta University for Science and Technology

Coastal International Road, Mansoura, Gamasa City, Dakahlia, Egypt

E-mail: dusj@deltauniv.edu.eg

Journal homepage: www.deltauniv.edu.eg/dusj 


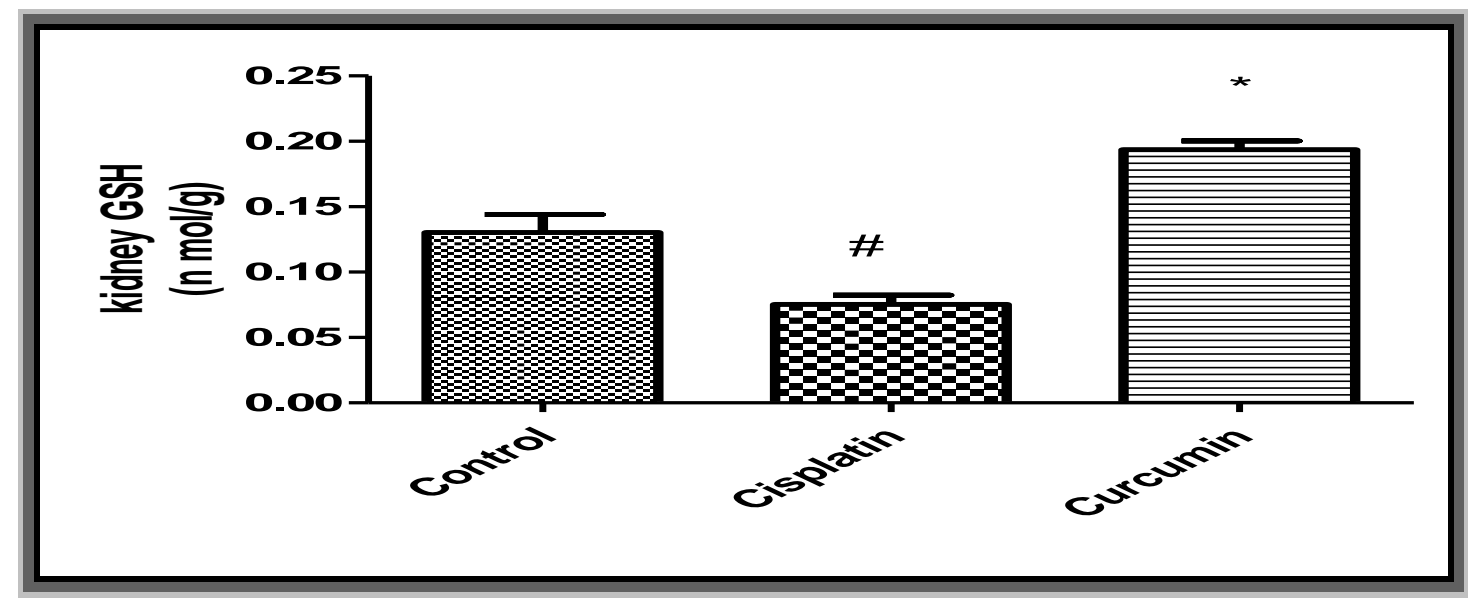

Figure 5: Effect of curcumin $(200 \mathrm{mg} / \mathrm{kg} / \mathrm{day})$ on kidney GSH level.

Values: (Mean \pm SD).

$\#=$ Significant against control group $\mathrm{p}<0.0^{\circ}$

$*=$ Significant against cisplatin group $\mathrm{p}<0.05$.

\section{Discussion}

Kidney fibrosis is the hallmark of chronic kidney disease progression and characterized by an exaggerated wound healing process with the production of renal scar tissue. It comprises both the glomerular and the tubulointerstitial compartments [28]. Cisplatin is a major antineoplastic drug used for the treatment of solid tumors. Its chief dose-limiting side effect is nephrotoxicity, which requires a reduction of dose or discontinuation of the treatment [26]. We here employed a cisplatin-induced fibrotic model in rats. Different rodent models of cisplatininduced nephrotoxicity have been described which include using single or multiple injections in rats [29]. We followed the dose regimen that has been described by Wu et al [3]. At the end of the experiment, alterations in serum levels of creatinine and urea nitrogen indicated kidney injury and disease.

Cisplatin caused the deterioration of renal function as shown by elevation of serum and urinary creatinine levels and reduction in creatinine clearance in accordance with previous reports [30, 31]. This may indicate glomerular damage as a consequence of reactive oxygen species (ROS) and increased free radicals. Previous reports have shown that cisplatin administration caused an increase in serum creatinine that peaks around day 7 and then returns to normal levels [32, 33]. However, these results were observed after one single dose of cisplatin and over a period shorter than our present study. One study was in agreement with our results and showed an increase in serum creatinine after 4 weeks of cisplatin administration [34]. Another study also showed an

Delta University for Science and Technology

Coastal International Road, Mansoura, Gamasa City, Dakahlia, Egypt

E-mail: dusj@deltauniv.edu.eg

Journal homepage: $\underline{w w w . d e l t a u n i v . e d u . e g / d u s j}$ 
elevation of creatinine levels after 56 days, an indication of sustained renal fibrosis and deterioration of renal function [35]. Curcumin treatments ameliorated the former parameters.

Oxidative stress plays a key role in cisplatin-induced renal dysfunction. Cisplatin enhances the production of superoxide, peroxynitrite, hydrogen peroxide and hydroxyl radicals via mobilization of iron from renal cortical mitochondria [26]. The enhanced expression of reactive oxygen species (ROS) by cisplatin is directly related to tubulointerstetial fibrosis [36]. Cisplatin is activated when it enters the cell through binding to the N7 reactive center on purine rings, resulting in DNA damage in cancer cells, blocking cell division and contributing to apoptotic cell death [37]. Cisplatin also induces ROS-mediated cell death [14]. ROS production increases during cisplatin treatment of cultured renal tubular cells, kidney slices, and in vivo in whole animals [38].

As a result of increased ROS production by cisplatin, antioxidant enzymes such as GSH are depleted [15]. Cisplatin also triggers MDA production in renal tissue [39]. Cisplatin can produce ROS through different mechanisms. Cisplatin can rapidly react with thiol-containing molecules, primarily glutathione [40]. Once glutathione and other antioxidants are consumed, a shift in the cellular redox status occurs. ROS then accumulates within the cell and causing a state of oxidative stress. [41]. ROS may also disrupt the respiratory chain and cause mitochondrial dysfunction. The cytochrome P450 system has also been reported to be responsible for generating ROS as demonstrated in in vitro and in vivo models [42, 43]. In this study, the antioxidant status was assessed by measuring GSH and MDA levels. Kidney MDA was significantly increased in cisplatin group compared to control group. However, GSH was significantly reduced in the cisplatin group when compared to the control group. Curcumin treatment significantly reduced MDA and were significantly increased GSH compared to cisplatin group $(\mathrm{p}<0.05)$.

Curcumin is known for its high oxygen-radical scavenging and quenching power [18]. It is a scavenger of free oxygen radicals and stimulates the activity of additional antioxidant molecules such as superoxide dismutase, catalase, and glutathione peroxidase [44]. It is a bifunctional antioxidant [45] because of its ability to react directly with reactive species and to induce an up-regulation of various cytoprotective and antioxidant proteins [46]. Curcumin can react with ROS through its phenolic and methoxy groups and it is thought to be one of the mechanisms through which it can protect the renal epithelial from ROS activity [47]. Curcumin can indirectly induce the expression of cytoprotective proteins such as superoxide dismutase (SOD), catalase (CAT) [48], GSH [49], nicotinamide adenine dinucleotide phosphate (NADPH), quinone oxidoreductase 1 (NQO1) [50]. Furthermore, it has been reported that curcumin can increase the 
synthesis and concentration of GSH [51].

In summary, this study demonstrated that curcumin can reverse changes by fibrosis induced experimentally in rats through the upregulation of antioxidants and suppression of oxidative stress markers. Curcumin is a promising therapy for management of kidney fibrosis. Further in vitro studies are needed to outline the signaling pathways involved in curcumin actions during fibrosis.

\section{References:}

1- Collins, A.J., et al., United States Renal Data System public health surveillance of chronic kidney disease and end-stage renal disease. Kidney international supplements, 2015. 5(1): p. 2-7.

2- El-Arbagy, A.R., Y.S. Yassin, and B.N.J.M.M.J. Boshra, Study of prevalence of end-stage renal disease in Assiut governorate, upper Egypt. 2016. 29(2): p. 222.

3- $\mathrm{Wu}$, H.H., et al., Monitoring the progression of renal fibrosis by T2weighted signal intensity and diffusion weighted magnetic resonance imaging in cisplatin induced rat models. Chin Med J (Engl), 2015. 128(5): p. 626-31.

4- Chen, H. and L.W. Busse, Novel Therapies for Acute Kidney Injury. Kidney Int Rep, 2017. 2(5): p. 785799.

5- Cerri, S., et al., The developmental neurotoxicity study of platinum compounds. Effects of cisplatin versus a novel Pt(II) complex on rat cerebellum. Neurotoxicol Teratol, 2011. 33(2): p. 273-81.

6- Di Francesco, A.M., A. Ruggiero, and R. Riccardi, Cellular and molecular aspects of drugs of the future: oxaliplatin. Cell Mol Life Sci, 2002. 59(11): p. 1914-27.

7- Chawla, L.S., et al., Acute kidney injury and chronic kidney disease as interconnected syndromes. $\mathrm{N}$ Engl J Med, 2014. 371(1): p. 5866.

8- Uccelli, A., L. Moretta, and V. Pistoia, Mesenchymal stem cells in health and disease. Nature Reviews Immunology, 2008. 8: p. 726.

9- Engle, J.E., Clinical physiology of acid-base and electrolyte disorders. JAMA, 1990. 263(17): p. 2375-2376.

10-Ciarimboli, G., et al., Cisplatin nephrotoxicity is critically mediated via the human organic cation transporter 2. Am J Pathol, 2005. 167(6): p. 1477-84.

11-Kang, D.G., et al., Butein ameliorates renal concentrating ability in cisplatin-induced acute renal failure in rats. Biol Pharm Bull, 2004. 27(3): p. 366-70.

12-Ozben, T., Oxidative stress and apoptosis: impact on cancer therapy. J Pharm Sci, 2007. 96(9): p. 2181-96.

13-Ozbek, E., Induction of oxidative stress in kidney. International journal of nephrology, 2012. 2012.

14-Brozovic, A., A. AmbriovicRistov, and M. Osmak, The relationship between cisplatininduced reactive oxygen species, glutathione, and BCL-2 and

Delta University for Science and Technology

Coastal International Road, Mansoura, Gamasa City, Dakahlia, Egypt

E-mail: dusj@deltauniv.edu.eg

Journal homepage: www.deltauniv.edu.eg/dusj 
resistance to cisplatin. Crit Rev Toxicol, 2010. 40(4): p. 347-59.

15-Sharma, S., A. Joshi, and S. Hemalatha, Protective Effect of Withania coagulans Fruit Extract on

Cisplatin-induced Nephrotoxicity in Rats. Pharmacognosy Research, 2017. 9(4): p. 354-361.

16- Altenburg, J.D., et al., A synergistic antiproliferation effect of curcumin and docosahexaenoic acid in SKBR-3 breast cancer cells: unique signaling not explained by the effects of either compound alone. BMC cancer, 2011. 11(1): p. 149.

17-Manolova, Y., et al., The effect of the water on the curcumin tautomerism: A quantitative approach. Spectrochimica Acta Part A: Molecular and Biomolecular Spectroscopy, 2014. 132: p. 815-820.

18-Al-Jassabi, S., K.-A. Ahmed, and M.A. Abdulla, Antioxidant effect of curcumin against microcystin-LRinduced renal oxidative damage in Balb/c mice. Tropical Journal of Pharmaceutical Research, 2012. 11(4): p. 531-536.

19- Tajbakhsh, S., et al., Antibacterial activity of indium curcumin and indium diacetylcurcumin. African Journal of Biotechnology, 2008. 7(21).

20-Bereswill, S., et al., Antiinflammatory effects of resveratrol, curcumin and simvastatin in acute small intestinal inflammation. PloS one, 2010. 5(12): p. e15099.

21-Kutluay, S.B., et al., Curcumin inhibits herpes simplex virus immediate-early gene expression by a mechanism independent of p300/CBP histone acetyltransferase activity. Virology, 2008. 373(2): p. 239247.

22-Das, L. and M. Vinayak, Anticarcinogenic action of curcumin by activation of antioxidant defence system and inhibition of $N F-\kappa B$ signalling in lymphoma-bearing mice. Bioscience reports, 2012. 32(2): p. 161-170.

23-Aziz, M.T.A., et al., Signaling mechanisms of a water soluble curcumin derivative in experimental type 1 diabetes with cardiomyopathy. Diabetology \& metabolic syndrome, 2013. 5(1): p. 13.

24- Elhusseini, F.M., et al., Long Term Study of Protective Mechanisms of Human Adipose Derived Mesenchymal Stem Cells on Cisplatin Induced Kidney injury in Sprague-Dawley Rats. J Stem Cells Regen Med, 2016. 12(1): p. 36-48.

25-Lian, N., et al., Curcumin regulates cell fate and metabolism by inhibiting hedgehog signaling in hepatic stellate cells. Lab Invest, 2015. 95(7): p. 790-803.

26-Kuhad, A., et al., Renoprotective effect of Spirulina fusiformis on cisplatin-induced oxidative stress and renal dysfunction in rats. Renal failure, 2006. 28(3): p. 247254.

27-Sharma, A., et al., Safety and blood sample volume and quality of a refined retro-orbital bleeding technique in rats using a lateral approach. Lab Anim (NY), 2014. 43(2): p. 63-6.

Delta University for Science and Technology

Coastal International Road, Mansoura, Gamasa City, Dakahlia, Egypt

E-mail: dusj@deltauniv.edu.eg

Journal homepage: $\underline{w w w . d e l t a u n i v . e d u . e g / d u s j}$ 
28-Ostendorf, T., et al., Plateletderived growth factors (PDGFs) in glomerular and tubulointerstitial fibrosis. Kidney international supplements, 2014. 4(1): p. 65.

29-Perse, M. and Z. Veceric-Haler, Cisplatin-Induced Rodent Model of Kidney Injury: Characteristics and Challenges. Biomed Res Int, 2018. 2018: p. 1462802.

30-Kamel, K.M., et al., Protective effects of onion oil and selenium against cisplatin-induced nephrotoxicity and oxidative stress in rats. Egyptian Journal of Hospital Medicine (Jan. 2015), 2015. 58: p. 18-25.

31-El-Sayed, E.-S.M., A.M. Mansour, and M.Y. Ghobara, Abrogation of cisplatin-induced nephrotoxicity in rats by Berne date extract through ameliorating oxidative stress, inflammation and apoptosis. International Journal of Pharma Sciences and Research (IJPSR), 2015. 6(9).

32-Bulacio, R.P. and A.M. Torres, Time course of organic anion transporter 5 (Oat5) urinary excretion in rats treated with cisplatin: a novel urinary biomarker for early detection of drug-induced nephrotoxicity. Arch Toxicol, 2015. 89(8): p. 1359-69.

33-Zhou, H., et al., Exosomal Fetuin-A identified by proteomics: a novel urinary biomarker for detecting acute kidney injury. Kidney Int, 2006. 70(10): p. 1847-57.

34-Elseweidy, M.M., et al., Nephrotoxicity Induced by Cisplatin Intake in Experimental Rats and Therapeutic Approach of
Using Mesenchymal Stem Cells and Spironolactone. Appl Biochem Biotechnol, 2018. 184(4): p. 13901403.

35-Kawai, Y., et al., The effect of antioxidant on development of fibrosis by cisplatin in rats. 2009. 111(4): p. 433-439.

36-Kawai, Y., et al., The effect of antioxidant on development of fibrosis by cisplatin in rats. $\mathrm{J}$ Pharmacol Sci, 2009. 111(4): p. 433-9.

37-Dasari, S. and P.B. Tchounwou, Cisplatin in cancer therapy: molecular mechanisms of action. European journal of pharmacology, 2014. 740: p. 364-378.

38-Kawai, Y., et al., The effect of antioxidant on development of fibrosis by cisplatin in rats. Journal of pharmacological sciences, 2009. 111(4): p. 433-439.

39-Niles, D.J., et al., Evaluation of renal metabolic response to partial ureteral obstruction with hyperpolarized 13 C MRI. NMR Biomed, 2017.

40-4Siddik, Z.H., Cisplatin: mode of cytotoxic action and molecular basis of resistance. Oncogene, 2003. 22(47): p. 7265-7279.

41- Liu, H. and R. Baliga, Cytochrome P450 2E1 null mice provide novel protection against cisplatininduced nephrotoxicity and apoptosis. Kidney international, 2003. 63(5): p. 1687-1696.

42- Baliga, R., et al., In vitro and in vivo evidence suggesting a role for iron in cisplatin-induced nephrotoxicity. Kidney 
international, 1998. 53(2): p. 394401.

43-Pabla, N. and Z. Dong, Cisplatin nephrotoxicity: mechanisms and renoprotective strategies. Kidney international, 2008. 73(9): p. 9941007.

44-Topcu-Tarladacalisir, $\quad$ Y., $\quad$ M. Sapmaz-Metin, and T. Karaca, Curcumin counteracts cisplatininduced nephrotoxicity by preventing renal tubular cell apoptosis. Ren Fail, 2016. 38(10): p. 1741-1748.

45-Dinkova-Kostova, A.T. and P. Talalay, Direct and indirect antioxidant properties of inducers of cytoprotective proteins. Mol Nutr Food Res, 2008. 52 Suppl 1: p. S128-38.

46- Ak, T. and I. Gulcin, Antioxidant and radical scavenging properties of curcumin. Chem Biol Interact, 2008. 174(1): p. 27-37.

47-Cohly, H.H., et al., Effect of turmeric, turmerin and curcumin on H2O2-induced renal epithelial (LLC-PK1) cell injury. Free Radic Biol Med, 1998. 24(1): p. 49-54.

48-Panchal, H.D., et al., Early antioxidative and anti-proliferative curcumin effects on neuroglioma cells suggest therapeutic targets. Neurochem Res, 2008. 33(9): p. 1701-10.

49- Yarru, L.P., et al., Effects of turmeric (Curcuma longa) on the expression of hepatic genes associated with biotransformation, antioxidant, and immune systems in broiler chicks fed aflatoxin. Poult Sci, 2009. 88(12): p. 2620-7.
50- Ye, S.F., et al., Effect of curcumin on the induction of glutathione $S$ transferases and $N A D P(H)$ :quinone oxidoreductase and its possible mechanism of action. Yao Xue Xue Bao, 2007. 42(4): p. 376-80.

51-Lavoie, S., et al., Curcumin, quercetin, and $t B H Q$ modulate glutathione levels in astrocytes and neurons: importance of the glutamate cysteine ligase modifier subunit. J Neurochem, 2009. 108(6): p. 1410-22.

Delta University for Science and Technology

Coastal International Road, Mansoura, Gamasa City, Dakahlia, Egypt

E-mail: dusj@deltauniv.edu.eg

Journal homepage: www.deltauniv.edu.eg/dusj 